\title{
Lucha sindical docente. Un análisis de la resistencia gremial en Santa Cruz, Argentina
}

\author{
Teachers' union struggle. An analysis of trade union \\ resistance in Santa Cruz, Argentina
}

\author{
Gerardo Avalle \\ Universidad Católica de Córdoba \\ (Argentina) \\ avallegera@gmail.com
}

\section{Resumen}

El presente trabajo ofrece una lectura de la contienda sindical docente en Santa Cruz, haciendo énfasis en dos eventos contenciosos centrales, ocurridos en 2004 y 2007. El abordaje propuesto pretende, desde una mirada microfísica, desde la palabra y la práctica de los actores sindicales, reconstruir el ciclo de contiendas, los repertorios de lucha, y los procesos de subjetivación que emergen de los conflictos, atentos especialmente a la operatorias y dispositivos estatales puesto a jugar en la contienda. Efectuamos el análisis a partir de entrevistas en profundidad realizadas a los docentes sindicalizados, recurriendo especialmente a las técnicas de análisis del discurso de marcos o "enmarcado de la acción".

Palabras Clave: Sindicatos, Acción colectiva, Subjetivación

\begin{abstract}
The present paper offers an interpretation of the teachers' union dispute in Santa Cruz, emphasizing two central contentious events, which took place in 2004 and 2007. The proposed approach seeks (from a microphysical perspective, from the discourse and practice of the union actors) to reconstruct the cycle of
\end{abstract}


contentions, the repertoires of struggle, and the processes of subjectivation that emerge from the conflicts, paying special attention to the operatives and state devices put into play. We conducted the analysis based on in-depth interviews with unionized teachers, using the techniques of analysis of discourse and of frames or "framing of action".

Key Words: Unions, Collective action, Subjectivity

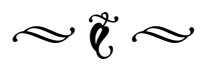

\section{Introducción ¿Desde dónde narramos?}

La contienda sindical docente de Santa Cruz reviste una particularidad especial que emerge de los relatos de los entrevistados. ${ }^{1}$ Los documentos que hemos trabajado, las técnicas aplicadas y las dimensiones conceptuales abordadas muestran aquí una estructuración singular que seguiremos para exponer la configuración de este conflicto.

Santa Cruz es una de las provincias más australes del país, el último territorio del continente. Las distancias son enormes, de poca población y un clima hostil. Muchos de los residentes no son nacidos en la provincia sino que hicieron de su estadía un proyecto de vida. Con tres décadas de gobierno peronista, ${ }^{2}$ la dinámica que

1. La elaboración de este trabajo se efectúa a partir de las entrevistas realizadas a los militantes del gremio docente. Otras fuentes serán señaladas en el caso oportuno. Los extractos de las entrevistas son referenciados con un número que indica la entrevista realizada a los docentes de la organización sindical estudiada, seguida por otro número que indica el orden de la cita que hemos extraído de la unidad hermenéutica.

2. El trabajo realizado por AUZOBERRÍA, Miguel, Los días de Cépernic. Una historia del Peronismo de Santa Cruz, Editorial Dunken, Buenos Aires, 2014, es una interesante logró imprimir el partido de gobierno ha sido muy particular: un sistema político cerrado a las demandas, fuerte generador de empleo público y una penetración partidaria e institucional significativa en el territorio, lo que le permitió controlar y/o desactivar cualquier tipo de confrontación y oposición al ejecutivo provincial. Sin embargo, esta economía del poder empieza a mostrar sus fisuras desde el mismo momento en que se activa la sucesión institucional cuando el entonces gobernador Néstor Kirchner es elegido presidente en el año 2003.

$\mathrm{Al}$ año siguiente de la elección comienza, de modo incipiente, a modificarse el repertorio de acción sindical docente, no en términos de innovación sino de recuperación de la medida de fuerza más clásica del sindicalismo, como la huelga. Sin éxitos aparentes, el sector docente queda fuertemente golpeado. A pesar de ello, la experiencia es convertida en una oportunidad para reorganizarse y preparar una nueva confrontación. En la narrativa de los entrevistados aparece de modo unánime y permanente la referencia a este episodio de 2004 para

obra que recupera las tensiones entre el peronismo digitado en Buenos Aires, y las expresiones locales o provinciales. 
inscribir el prolongado conflicto que sostuvieron con el gobierno provincial en el año 2007. Pero es especialmente a partir de estos últimos eventos de la contienda que se estructuran todas esas narrativas.

También aparece otra dimensión, que es la que habla de la militancia: el involucramiento en el conflicto, la participación ciudadana que estalla en las calles, las líneas políticas internas y la construcción de los liderazgos, la formación de referentes sindicales, el encuentro de dos generaciones de militantes iniciados en el retorno de la democracia, la presencia de la mujer en los conflictos y el registro que el cuerpo hace de la lucha.

En definitiva, lo que aquí proponemos y hacemos es presentar dos modos de narrar la contienda, uno organizado a partir del conflicto central y la construcción del adversario. E1 otro, hecho a partir de la experiencia biográfica y corporal de la militancia sindical y la participación de los y las docentes en las acciones colectivas. Estas dos formas de exposición son también dos modos de abordar la conflictividad sindical. Las hipótesis aquí trabajadas dan cuenta, por un lado, desde la narrativa del conflicto, cómo las oportunidades políticas van configurando el escenario y habilitando o cercenando procesos de confrontación y demandas sociales. En este sentido, la represión y el control político del estado operan como diques de contención, pero las estrategias de alianzas y generalización de marcos ideológicos y la construcción procesual de las acciones colectivas se presentan como un recurso posible de alterar las relaciones de fuerza. Por otro lado, desde la perspectiva biográfica, sostenemos que los conflictos cobran corporeidad, más allá de la obvia experiencia física de lo vivido, performando el modo de habitar los espacios y construir los discursos. Así, la lucha se hace cuerpo, y la subjetivación o construcción de identidades políticas aparece como el nexo de estas dos miradas de la lucha.

Inevitablemente estas dos dimensiones nos remiten a un conjunto de lecturas que la literatura académica ha ubicado dentro de lo que se conoce como acciones colectivas, repertorios contenciosos y procesos de configuración de subjetividades. Las dos primeras tradiciones teóricas sostienen que es la práctica pública, colectiva, con intereses claros, compartidos y dirigidas a un adversario común, la que nos habilita a comprender la diversidad de escenarios políticos contemporáneos. Los repertorios de acción son justamente la herramienta conceptual que nos permite valorar, en el tiempo, la dinámica y el carácter que asumen esas contiendas, el tipo de repertorios, nivel de confrontación y ciclos de conflicto. ${ }^{3} \mathrm{Y}$ es finalmente desde los procesos de subjetivación, ya sea analizados desde perspectivas posestructurales donde es en la instancia discursiva, constitutiva

3. En este enfoque se ubican las producciones sobre nuevos movimientos sociales, oportunidad política y movilización de recursos. Seguimos, entre otros autores, a MELUCCI, Antonio, L'invenziones del presente: movimiento, identità, bisogni individuali, Il Mulino, Bologna, 1982; McADAM, Doug, TARROW, Sidney y TILLY, Charles, Dinámica de la contienda política, Hacer Editorial, Barcelona, 2005; DELLA PORTA, Donatella, "Protest, Protesters, and Protest Policing: Public Discourses in Italy and Germany from the 1960's to the 1980's", en GIUGNI, Marco, MCADAM, Doug, y TILLY, Charles, How Social Movements Matter, University of Minnesota Press, Minneapolis, 1999, pp. 66-96; CROUCH, Colin y PIZZORNO, Antonio, El resurgimiento del conflicto de clases en Europa occidental a partir de 1968, Centro de Publicaciones, Ministerio de Trabajo y Seguridad Social, Madrid, 1991; TOURAINE, Alaine, Los Movimientos Sociales, Almagesto, Buenos Aires, 1991; TARROW, Sidney, El poder en movimiento. Los movimientos sociales, la acción colectiva y la política, Alianza, Madrid, 1997. 
de lo real, donde los sujetos cobran una entidad política específica y le dan sentido a lo que los rodea; ${ }^{4}$ o desde las perspectivas obreristas italianas, ${ }^{5}$ que es en las instancias de lucha y conflicto donde emergen esas subjetividades de clase, que uno puede dar cuenta de la relevancia histórica y el impacto político que han tenido una serie de eventos contenciosos, que aquí decidimos delimitar como la contienda sindical santacruceña.

Realizamos, en este sentido, lo que podemos llamar un análisis de la microfísica de las prácticas sindicales, un punto de arranque para pensar los modos en que el poder (y las relaciones que en torno a éste se entretejen), va produciendo formas de vida; al tiempo que las prácticas más reticulares y moleculares que los actores políticos despliegan, terminan por prefigurar nuevas subjetividades en el escenario social. El concepto de poder que aquí utilizamos es deudor de la obra de Foucault, ${ }^{6}$ quien lo define como "relación", "ejercicio", "móvil", en tanto este no se encuentra fijado ni es inherente a un espacio o institución, no se detenta, y su principal característica es su circulación por todos los espacios y cuerpos. De ahí que se prefiera hablar de "relaciones de poder" que configuran prácticas específicas de dominio y

4. LAZZARATO, Maurizio, Politicas del Acontecimiento, Tinta Limón, Buenos Aires, 2006; GUATTARI, Félix y ROLNIK, Suely, Micropolitica. Cartografías del deseo, Tinta Limón, Buenos Aires, 2013; FOUCAULT, Michel, El orden del discurso, Tusquets, Buenos Aires, 1987; CHIGNOLA, Sandro y MEZZADRA, Sandro, "Fuera de la pura política. El laboratorio global de la subjetividad", en ALTAMIRA, Carlos, Politica y subjetividad en tiempos de governance, Waldhuter, Buenos Aires, 2013, pp. 203-234.

5. ALTAMIRA, Carlos, Los marxismos del nuevo siglo, Biblos, Buenos Aires, 2006; NEGRI, Toni, Fin de siglo, Barcelona, Paidós, 1992.

6. FOUCAULT, Michel, El orden... Op. Cit. desobediencia, sedimentan en tecnologías de gobierno y dispositivos de control y disciplina. Esta concepción de poder requiere una lectura "microfísica", y por lo tanto la puesta en práctica de esa relación, el funcionamiento de esos mecanismos y dispositivos. Al igual que el concepto de "acontecimiento", se termine por asociar el concepto de poder a los de lucha, táctica y estrategias de poder. Por otro lado, la noción de subjetividad no refiere a una posición psicologista que reduce el término a cuestiones internas del individuo, sino a las perspectivas postestructurales que asocian el concepto a la idea de producción de sujetos colectivos, ya sea sujetados al modo de producción, o ligados a sí mismos como forma de reconocimiento y afirmación. En ese sentido, cuando hablamos de subjetividades, lo hacemos en términos colectivos, y centrados específicamente en los procesos que las habilitaron.

Hacemos uso de las técnicas provenientes del análisis de discurso y de contenido para abordar una serie de prácticas (textualizadas) que dan cuenta de cada evento y cada proceso subjetivo. Enfatizamos especialmente en aquellos contenidos recurrentes, significativos, que organizan campos semánticos diferenciados y permiten reconstruir la trama discursiva de la contienda, y en consecuencia, desentramar las huellas de las condiciones de producción que le dieron lugar.

\section{Los opositores de siempre. La conformación de ADOSAC}

El proceso contencioso que estudiamos es el que tiene por protagonista a la Asociación de Docentes de la Provincia de Santa Cruz (en adelante, ADOSAC). Este gremio forma 
parte de Confederación de Trabajadores de la Educación de la República Argentina (en adelante, CTERA). ADOSAC se conforma en el año 1961 ante la necesidad de la organización y regularización del sector y el reclamo por la sanción del Estatuto Docente, demanda común a todas las organizaciones docentes en ese tiempo.

En sintonía con otros gremios, luego del regreso de la democracia y tras varios años de proscripción, durante la década del '80, ADOSAC inicia su recomposición, posicionándose como uno de los principales actores del escenario provincial con capacidad de influencia en el curso de la política local. Si bien recupera el estatus jurídico como asociación en 1981, recién en 1988 le son aprobados sus estatutos por el Ministerio de Trabajo de la Nación (Res. No 503-1993), y en 1993 queda registrada su personería gremial № 1504 (Res. No 166-1993) otorgada por la misma dependencia nacional, habilitándola a actuar en representación del sector frente al Estado. ${ }^{7}$

A pesar de ser la provincia que mayores recursos recibió del Ministerio de Educación $\mathrm{Na}-$ cional, fue en la que menos cambios se registraron en relación a las leyes y/o procesos de reforma educativa promovidos a nivel nacional. ${ }^{8}$ La ley de educación provincial data de la década del '60. La provincia no promovió una reforma integral, sino que permanentemente fue adaptando la política educativa mediante “acuerdos" emanados por el Consejo Provincial

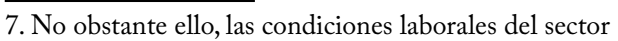
y su representación se encontraban reguladas por la Ley Nacional No 14.473 de 1958 y las normas que cada jurisdicción derivare de ella.

8. CARDINI, Alejandra y GESSAGHI, Victoria, "Provincia de Santa Cruz", en Informe Proyecto Las provincias educativas, CIPPEC, Buenos Aires, 2003, p. 9. de Educación y decretos ley del ejecutivo provincial, una operatoria más local y de menor generación de consensos. Los ajustes se iban efectuando anualmente, acorde a las modificaciones de la política educativa nacional, que a través de los conocidos "pactos educativos" comprometía nuevos fondos para aquellas jurisdicciones que fueran adaptando su sistema.

Bajo la misma dirección política provincial, durante toda la década se desempeñaron en el área educativa tres funcionarios cuyos perfiles políticos han sido completamente diferentes al igual que sus gestiones. La primera etapa (1991-1995) orientada a reordenar el sistema educativo y disminuir el nivel de conflictividad, apaciguó el conflicto docente implementando el mecanismo de "presentismo" como parte del salario y reorganizando administrativamente la gestión educativa. ${ }^{9}$

La segunda (1995-1999) importó cambios más significativos y la dirección fue más política que de gestión, con fuertes niveles de enfrentamiento en tanto se diseñaron los cambios pedagógicos que debía asumir el sistema educativo provincial, en el marco de la implementación de la Ley Federal de Educación. ${ }^{10}$ Finalmente, la tercera (1999-2003) llevó adelante la implementación de cambios "negociados" con el gremio, ahora bajo una conducción enfrentada al gobierno provincial.

9. Parte del salario que se otorga como "premio" por asistencia perfecta. Durante los años '90 llegó a representar gran parte del salario docente, por lo que una inasistencia, por motivos personales o huelga, inmediatamente privaba de este "beneficio".

10. En este período se sanciona la reforma de la Ley Provincial de Educación No 263/61 de 1963, siendo reemplazada por la Ley no 2.411 de 1995. 
El cambio de la dirección política provincial en 2003- donde el gobernador de entonces es electo presidente de la nación- ${ }^{11}$ pero en el marco de la continuidad del partido gobernante en el ejecutivo local, significó una reacomodación de las relaciones de fuerza, un reposicionamiento de los gremios que representaban a los empleados públicos y, especialmente, una reconfiguración de la contienda acorde a los cambios políticos-institucionales y económicos que atravesaba el país.

En el año 2007, el enfrentamiento con los niveles provincial y nacional del poder ejecutivo posicionó el conflicto docente de Santa Cruz en la agenda pública nacional. El saldo de este enfrentamiento fue un alto nivel de conflictividad, "judicialización" de militantes, ${ }^{12}$ la renuncia del gobernador provincial y la reinstalación de las paritarias salariales para los empleados públicos.

Una experiencia previa tuvo lugar en el año 2004, cuando una de las filiales más grandes del gremio docente, Caleta Olivia, al norte de la provincia, inicia una huelga por tiempo indeterminado a la que luego adhieren el resto de las filiales, pero por problemas internos en el gremio y el efecto del "presentismo", la

11. El gobernador de ese momento era Néstor Kirchner, quien renuncia al cargo al ser electo Presidente de la Nación.

12. Este término hace referencia a los procesos de traducción de la conflictividad social en términos jurídicos, esto es, el inicio de causas penales por parte del Estado contra los militantes sindicales o participantes de las acciones colectivas. La bibliografía local denomina a este proceso como "judicialización o criminalización de la protesta". Ver entre otros: BAKMAS Gabriel, Integración, exclusión y criminalización de la protesta, Felafacs, Santiago de Chile, 2002; SVAMPA, Maristella y GARGARELLA, Roberto, "El derecho y la protesta social”, Página 12, Buenos Aires, 04/11/2003. medida de fuerza logra ser "quebrada" por el gobierno provincial.

\section{Episodios y eventos de confrontación previos: la huelga simbólica y la ausencia del diálogo}

La combatividad del gremio resultaba una amenaza para el nuevo gobierno que justamente asumía en un contexto de fuerte confrontación con los empleados públicos a principios de los $90 .{ }^{13}$ En consecuencia, el accionar estatal estuvo dirigido deliberadamente a minar el poder de fuego sindical e invertir la correlación de fuerzas existente.

De ahí que el deterioro institucional del gremio fuera considerable desde el primer día de inicio de la gestión kirchnerista en la provincia. Son canceladas las licencias gremiales, derecho reconocido por la Ley Nacional de Asociaciones Sindicales, ${ }^{14}$ lo que llevó a quienes ocuparon cargos de dirigencia a desempeñarlos fuera de sus horarios de trabajo. Los aportes sindicales fueron embargados, lo que dificultó sostener la administración de las filiales más pequeñas, entre otra serie de complicaciones que tornaron mucho más costosa la organización y sostenimiento del espacio colectivo. ${ }^{15}$

13. Ver, entre otros, la sistematización realizada por LUQUE, Élida, MARTÍNEZ, Susana, AUZOBERRÍA, Miguel y HUENUL, Hugo, "Conflictos sociales en la provincia de Santa Cruz. Los años noventa”, en Documento de Trabajo No 41, PIMSA, Buenos Aires, 2003.

14. Ley Nacional no 23.551/88.

15. Solo a modo indicativo de estas afirmaciones podemos recuperar el Decreto Provincial No 704/90 que dispone "el descuento de haberes por los días no laborados al personal docente y de la administración 
Y veníamos de una situación de muchos años de derrota, de apaciguamiento. Desde que asumió Kirchner, Kirchner asume en diciembre del 91, él comenzó un proceso de tratar de poner orden en la vida de los gremios... la primera medida importante que tomó, además de una ley de emergencia, anularon varios derechos importantes... El tipo entró rebajando sueldos, anulando el aumento salarial que había dado el gobierno anterior... Así que entró pisando fuerte, no era ajuste, era recontra requete ajuste. ${ }^{16}$

Santa Cruz fue la primera provincia en implementar el adicional salarial por asistencia perfecta conocido como "presentismo". Lo hizo en el año 1991, cuando asume el gobernador Kirchner, en medio de una crisis económica de la administración provincial.

La percepción docente respecto de esta medida es homogénea: su objetivo fue "quebrar los conflictos". Al comprometer fuertemente el cálculo del salario, la ausencia a los lugares de trabajo implicaba perder gran parte de los ingresos, además del descuento de los días no trabajados. No contemplaba excepciones, ni enfermedad, ni embarazo. La presión fue muy alta, y se mantuvo vigente durante 16 años.

Y el presentismo era algo, significaba casi el $50 \%$ del salario que te pagaban para que vos vayas a dar clases, si vos faltabas un día perdías el presentismo. Te enfermabas, perdías el presentismo. Si... eh... no lo hicieron con el afán de que la gente no falte sino con... para romper la huelga docente... romper la lucha docente. ${ }^{17}$

pública provincial”, o el Decreto Provincial No 888/90, que apercibe con cesantía a los docentes en conflicto.

16. Entrevista 9.4, realizada por Gerardo Avalle, el 8 de febrero de 2011.

17. Entrevista 1.9, realizada por Gerardo Avalle, el 1 de más de un 40\% del salario ¿qué implicaba el presentismo? que cualquier docente que pedía carpeta médica y, hasta el año 2001 aquellas mujeres que tenían licencia por maternidad, directamente perdían... en esos seis meses no cobraba el presentismo, se consideraba que no iba porque no quería. $^{18}$

Sin dudas, el mecanismo fue efectivo. Logró, en este sentido, disciplinamiento laboral y control del espacio público. Fue también una operatoria que intervino y dispuso los márgenes dentro de los cuales era posible una subjetividad sindical. Los docentes se vieron imposibilitados de movilizar a las bases gremiales ante la amenaza de no percibir ingresos salariales como consecuencia de las medidas de fuerza. Dada la imposibilidad de desplegar medidas de fuerza masiva y medir la relación con el Estado provincial, el gremio profundiza su discurso crítico no sólo contra la política salarial docente, sino que la extiende a todos los niveles de la administración provincial.

Y nosotros hicimos un proceso de acumulación de fuerzas, desde la reorganización del gremio, de militancia, de conciencia política y gremial, que llevó mucho trabajo... vos pensá que desde el 97 fueron diez años de preparación para poder lograr una huelga exitosa. ${ }^{19}$

En todo ese periodo, y durante 10 años más, el gobierno provincial nunca recibió a los representantes de los docentes. La reforma educativa avanzó, a pesar de la permanente crítica

enero de 2010.

18. Entrevista 7.22, realizada por Gerardo Avalle, el 7 de febrero de 2011.

19. Entrevista 9.10, realizada por Gerardo Avalle, el 8 de febrero de 2011. 
docente. La disciplina gremial estaba rota, la disidencia salía de los espacios orgánicos que habían sido vaciados y hacía de su voz y de la calle el vehículo de denuncia y resistencia. Con un discurso capilar y germinal se va generalizando la necesidad de recuperar la principal herramienta colectiva de intervención en la contienda política.

Claro, claro, con fondos propios si no teníamos fondos, con nuestros vehículos personales, con la plata nuestra, a dormir donde nos tiraran el colchón, que en ese sentido los compañeros son absolutamente solidarios, enseguida te alojan en su casa, todo. No, estuvimos porque, bueno, por supuesto, ante la asunción nuestra que éramos opositores confesos al gobierno, descargaron todo para anularnos... primero legalmente no lo pudieron hacer, entonces nos descargaron todos los embargos habidos y por haber. ${ }^{20}$

En el año 1997, luego de una importante elección es derrotada la lista oficial, de extracción peronista, por la lista "rosa". Al intentar poner en funciones a las autoridades electas, la lista triunfante se encuentra con que la "conducción" saliente había impugnado las elecciones ante las autoridades nacionales y estas habían accedido a la demanda. No obstante, los docentes logran acceder a las instalaciones del gremio y deciden "tomarlo" de modo pacífico hasta tanto se reconociera el derecho que estaba siendo violentado.

La lista opositora a la conducción gremial de ese entonces gana, trata de hacer impugnaciones de todo tipo, bueno... hubo que entrar acá prácticamente por la fuerza a tomar el gremio, y desde ahí, a partir de

20. Entrevista 11.10, realizada por Gerardo Avalle, el 10 de febrero de 2011. ahí empieza el giro y la estrategia gremial diferente. ${ }^{21}$

El gremio contó en esta oportunidad con la colaboración de la CTERA, dirigida por una línea gremial opositora a la línea local. Los dirigentes nacionales solicitaron al Ministerio de Trabajo de la Nación el reconocimiento de la lista ganadora como autoridades legítimamente elegidas y designadas por los docentes de Santa Cruz al frente del sindicato. Esta acción saldó el conflicto, y comenzó una etapa dentro del gremio que consistió en un endurecimiento de la crítica, mayor presencia simbólica a partir de medidas de acción directa fuera de los horarios laborales y fuerte intervención en los conflictos sociales de la provincia. La nueva conducción sindical empezó a imprimir a su política gremial un perfil mucho más combativo y autónomo del gobierno.

En un escenario fuertemente adverso, ese trabajo estuvo acompañado por varias acciones colectivas de denuncia e impugnación al orden vigente, además de las de reclamo y reivindicación. Durante el año 2000 instalaron una "carpa" frente al Consejo de Educación para reclamar la reincorporación de los docentes que habían quedado sin cargo a partir de una nueva reforma del sistema educativo.

Luego, con el trasfondo de la crisis que atravesó el país a finales del año 2001, el gremio de ADOSAC adoptó los "cacerolazos" -el repertorio más difundido en la población por entonces- para reclamar por mejores salarios. Esta acción fue cobrando fuerza y durante varios meses, los días viernes, en las calles y edificios públicos se congregaban un conjunto de

21. Entrevista 10.6, realizada por Gerardo Avalle, el 10 de febrero de 2011. 
personas para manifestarse contra la gestión provincial.

Acá entra en escena un episodio que luego sería identificado de manera asidua en todas las acciones del gremio. Son los enfrentamientos entre quienes manifestaban y quienes actuaban en defensa del gobierno: las patotas, los golpes, atentados, incendios, etc., se tornaron frecuentes. Como sostiene María Ciuffolini, ${ }^{22}$ un uso de la violencia extendida a toda la sociedad como un modo de dirimir los conflictos internos entre las fracciones de poder.

Cacerolazo de los días viernes. Que se instauró como un método desde enero del 2002 ... salimos a convocar y empezó a juntarse gente, juntarse gente... Y siempre se hacía una manifestación en el centro y se marchaba a la Casa de Gobierno o a casa de un funcionario a hacer un escrache o cosas por el estilo... los tipos organizan una vez... hubo un enfrentamiento ahí entre las barras, la barra oficialista y la barra combativa, digamos... ese día cuando salimos de la cámara me habían destrozado el auto. ${ }^{23}$

Esta etapa fue percibida de manera contradictoria por los docentes. Para algunos consistió en una mayor radicalización del gremio, que no implicó mayor eficacia en el reclamo ante el Estado. Para otros resultó en una experiencia que les otorgó una presencia pública en el escenario político local, un espacio de denuncia y visibilización de las condiciones de trabajo y, sobre todo, estimuló la formación de referentes político-gremiales que comenzarían luego a operar en las bases sindicales, activan-

22. CIUFFOLINI, María, Resistencia y Conflicto: Luchas Sociales Urbanas en Córdoba post-2001, EDUCC, Córdoba, 2010.

23. Entrevista 9.13, realizada por Gerardo Avalle, el 8 de febrero de 2011. do instancias subjetivantes que permitirían trascender la fragmentación y singularización existente. $^{24}$

En realidad, el cambio se produjo como resultado de la derrota de 2004, yo creo que, porque hubo una involución, hubo una especia de... de volver atrás, en el sentido de considerar que habíamos sido muy extremos en las formas de lucha que se habían adoptado. Y un sector de compañeros cuestionando la militancia política de muchos de los dirigentes. ${ }^{25}$

El cambio de dirección del ejecutivo provincial en el año 2004 alteró la correlación de fuerzas provinciales por más que la conducción política siguiera siendo del partido en el gobierno. Ese año, una de las filiales más combativas, Caleta Olivia, al norte de la provincia, sorprendió al gremio docente con la declaración de una huelga por tiempo indeterminado, reclamando aumento salarial, "blanqueo" de las sumas salariales en "negro" y eliminación del presentismo docente.

El relato generalizado de ese momento fue la "sorpresa" del resto de las filiales ante una decisión que no había sido acompañada por la "orgánica provincial”. La sorpresa no jugó a favor del gremio, sino que imposibilitó una reacción inmediata y mostró sus flancos débiles, siendo rápidamente atravesado por el control estatal. En este evento empezó a jugar fuertemente la idea de "solidaridad gremial" por parte de la

24. Parafraseando a GUATTARI, Félix y ROLNIK, Suely, Micropolitica..., Op. Cit., p. 176, quienes advierten que los procesos de subjetivación se ven siempre expuestos a instancias fuertemente fragmentarias, no obstante, adoptan dinámicas rizomáticas que permiten establecer redes capilares de acción y resistencia.

25. Entrevista 9.15, realizada por Gerardo Avalle, el 8 de febrero de 2011. 
estructura sindical. La cobertura gremial debía ser inmediatamente puesta a disposición para no dejar "desamparados" a los "compañeros". Al mismo tiempo, cada filial intentó promover la adhesión a la medida de fuerza. Sin embargo, los esfuerzos fueron en vano y el gobierno logró "quebrar" el conflicto, con serias consecuencias para los sectores que habían ejercido el "derecho de huelga".

Hemos tenido una experiencia bastante compleja en el año 2004 cuando Caleta Olivia por su cuenta saca un paro, inicia un paro por tiempo indeterminado, de entrada nomás. Primer día de clases no comienzan... entonces, hubo que salir en protección de los compañeros... ER: Pero no fue un paro... EO: No orgánico, no orgánico porque no lo declara el congreso, Caleta lo... ER: Es como la asamblea local. EO: La asamblea local se reúne, se juntan... mil personas, y deciden no ir a trabajar y bueno... se les dijo que era inorgánico pero bueno, fueron al frente. Fue un conflicto muy duro porque estaba Caleta solo. El Congreso declara a mitad de marzo, declara el paro para toda la provincia pero estaba el presentismo, entonces no todo el mundo se adhirió. Fue un conflicto muy complejo, donde nos derrotaron, porque no logramos el aumento, los compañeros de Caleta, algunos cobraron 10 pesos, les descontaron todo, ni las asignaciones familiares, nada. Pero bueno, ellos decidieron seguir... Se les dijo que era inorgánico pero fueron al frente... y bueno, una vez que estamos en el baile, tenemos que bailar todos, siempre hemos sido solidarios. Bueno, y ese conflicto, nos marcó y nos enseñó cómo tenían que ser los conflictos de ahí en más. ${ }^{26}$

26. Entrevista 6.12, realizada por Gerardo Avalle, el 7 de febrero de 2011.
El reclamo de "organicidad" es también un indicador de otro problema en las formas colectivas de organización política. La organicidad está operando como una restricción a la innovación. Sin embargo, la in-organicidad mostró en este caso la potencia creativa y transformadora de la estructura sindical. Pero los efectos no tardaron en ser percibidos. El "norte" $(\mathrm{Ca}-$ leta Olivia) sintió la virulencia de la represión de la conducción del gobierno al momento de cobrar un salario cero.

Caleta estaba muerto en esa época, por el tema del 2004, que había quedado muy golpeado. Había sido, les habían hecho descuentos del 100\% del sueldo y en Caleta habrán iniciado un paro... 50 compañeros nada más. ${ }^{27}$

Los fondos de huelgas se tornaron imprescindibles para sostener temporalmente a aquellos docentes más afectados, y como ejercicio previo para lo que vendría. Visto en retrospectiva, para muchos de ellos el conflicto más importante del gremio que tuvo lugar en 2007 se inició cuando acabó el de 2004: las bases político gremiales quedaron fuertemente movilizadas, la organización apareció como garante de la acción colectiva y principal generadora de procesos solidarios. $^{28}$

27. Entrevista 8.13, realizada por Gerardo Avalle, el 7 de febrero de 2011.

28. DELLA PORTA, Donatella y DIANI, Mario, Los movimientos sociales, CIS, Madrid, 2011, destacan precisamente que la organización se convierte en un garante de la acción en contextos de desmovilización, y es a su vez, un espacio de generación de lo común y relaciones de intercambio y solidaridad. 


\section{La percepción de múltiples factores y la construcción de la lucha (2004-2007)}

Durante el año 2007, varias provincias se encontraban con conflictos salariales que amenazaban el inicio del ciclo lectivo en sus territorios. Varias administraciones provinciales tenían ya vigentes el sistema de paritarias, lo que garantizaba ciertos espacios de negociación y diálogo entre el gobierno y los representantes gremiales. En muchas de ellas también se había eliminado el cuestionado sistema del presentismo.

En Santa Cruz, sin embargo, los docentes estaban por cumplir 16 años sin obtener una sola audiencia con el gobernador de la provincia, instancia que si habían logrado otros gremios. Tampoco contaban con paritarias, lo que tornaba aún más arbitraria la resolución de los conflictos y respuesta a las demandas del sector, al tiempo que las garantías de estabilidad laboral siempre eran inciertas ante la ausencia de concursos de titularización de cargos, lo que representaba un escenario laboral altamente precario.

No obstante estos condicionantes, en el escenario local se fueron combinando una serie de acontecimientos y factores que terminaron detonando una de las confrontaciones más largas que haya tenido el gremio docente de Santa Cruz. Entre ellos, la arbitrariedad y la soberbia de los funcionarios públicos, la permanente denostación al gremio y la docencia por parte de éstos, salarios desactualizados con sumas no remunerativas, una inflación que comenzaba a avanzar considerablemente sobre los ingresos. Se sumaba, además, un malestar generalizado por parte de la población que empezaba a rechazar públicamente un estilo de gobierno y uso de la instituciones republicanas por parte de las administraciones locales. Sin duda, todos estos factores operaban como incentivos negativos para la acción colectiva..$^{29}$ De no haber mediado un proceso de concientización y generalización de marcos de agravio e indignación, difícilmente la activación y sostenimiento de la acción hubieran sido posibles. ${ }^{30}$

Esas fueron las asambleas más numerosas, $\mathrm{y}$ fueron en las, las movilizaciones de mayor cantidad de gente. Y la gente estaría harta de tanto... de que siempre te estén pisando la cabeza y de que no puedas salir, entonces se animó a salir en contra del gobierno... Eh, qué lo detonó... la falta de respuesta del gobierno a las demandas salariales. ${ }^{31}$

Y bueno, se venían dando, este, distintas, eh, yo le llamaría cualidades para la situación. Porque, eh, se presentaba un gobierno bastante soberbio, eh, duro en algunas decisiones, que no aceptaba escuchar, no dialogaban. Y todo eso iba sumando agravantes a la situación. ${ }^{32}$

29. Tomamos el concepto de "incentivo" de los teóricos de la acción racional, pero desplazamos e incorporamos en su significado a la posición normativa propuesta por ELSTER, John, El cemento de la sociedad. Las paradojas del orden social, Gedisa, Barcelona, 1992, mostrando con ello la multiplicidad de motivaciones y condicionantes sobre la acción, que se alejan de un interés individual y de simple maximización de beneficios.

30. Según KLANDERMANS, Bert, "La construcción social de la protesta y los campos pluri organizativos", en GUSFIELD, Joseph, y LARAÑA, Enrique, (editores)

Los nuevos movimientos sociales: de la ideología a la identidad, CIS, Madrid, 1994. La trasformación de la indignación y el miedo en agravio genera "marcos de agravios" o su equivalente en oportunidades para la movilización o marcos para la acción.

31. Entrevista 1.24, realizada por Gerardo Avalle, el 1 de enero de 2010.

32. Entrevista 3.2, realizada por Gerardo Avalle, el 3 de febrero de 2011. 
Ese es el escenario con que se encontró la nueva conducción gremial a pocos meses de asumir su mandato, cuyos objetivos estaban prioritariamente centrados en profundizar el trabajo de base, acercarse a la docencia, sumar afiliados y recomponer la estructura gremial en cada filial. En ese contexto se celebró, a finales de febrero de 2007, el primer Congreso Provincial anual de ADOSAC.

El encuentro mostró una coincidencia importante entre todos los congresales: la demanda de avanzar con medidas de fuerza era unánime. Los riesgos eran altos, el antecedente frustrado de 2004 todavía se sentía en los cuerpos. Sin embargo, la indignación y la bronca ahora comenzaban a operar como categorías movilizadoras y la percepción, también generalizada, era que el escenario había cambiado. ${ }^{33}$ El vice-gobernador a cargo de la gobernación había renunciado y quien lo reemplazó había sido designado por la Legislatura Provincial, sin demasiadas credenciales para el cargo por parte de la ciudadanía.

El conflicto de 2007 involucró a todos los sectores de la docencia, organizados y no organizados, con y sin representación gremial. Y no sólo eso, sino que tuvo la capacidad de genera-

33. Recuérdese, en este sentido, la afirmación de Sidney Tarrow, respecto del carácter subjetivo de las Oportunidades Políticas, entendidas estas como una percepción de los actores en la contienda, a partir de la cual entiende que es más favorable o no iniciar un proceso de acción colectiva. TARROW, Sidney, El poder..., Op. Cit., p. 156. A ello le sumamos la importancia de que esa percepción se afinque en condiciones materiales claves, siguiendo a Toni Negri, vinculadas a la experiencia que se encuentran atravesando los actores y las posibilidades, antes negadas, que se abren como escenarios posibles. Lo que tenemos, en consecuencia, es la experimentación de un cambio de las relaciones de fuerzas en el espacio público. NEGRI, Toni, Fin de..., Op. Cit. lizar el reclamo y canalizar la demanda social de mayor participación, convirtiéndose en un reclamo "ciudadano".

En este sentido, las lecturas que ofrecen los entrevistados se organizan en dos grandes dimensiones. Una sostiene que el conflicto fue producto de años de acumulación de fuerza y resistencia por parte del gremio. Sin dudas, esta posición se asocia a quienes han formado parte de las instancias deliberativas y decisorias del sector, acompañado las medidas de fuerza y atravesado numerosas situaciones de enfrentamiento con el Estado provincial. Esta perspectiva prevalece en aquellos y aquellas docentes que han encontrado en la actividad gremial el sentido de su militancia.

En el 2004 recién hubo una gran huelga con epicentro en Caleta Olivia, que no llegó a tener el peso en toda la provincia, y nos derrotó la unión... Pero fue un ensayo general de una lucha que... fue muy valioso el sacrificio que se hizo en ese momento. Y en el 2007 se dio de nuevo una gran huelga y esta vez sí la ganamos, bajaron presentismo, se blanquearon los sueldos, se celebró un aumento salarial muy importante, bueno, prácticamente cambiaron todas las relaciones de fuerzas, todas las relaciones de fuerzas, incluso cayó el gobierno por motivo de esa huelga docente en 2007. Entonces, digamos, desde el punto de vista de las luchas importantes, grandes y demás, fue todo un proceso de acumulación de fuerzas que se inició en el 97 con la subida de una nueva conducción. $^{34}$

La otra perspectiva encuentra en los acontecimientos de 2007 una oportunidad para comprometerse, el momento de "toma de concien-

34. Entrevista 9.6, realizada por Gerardo Avalle, el 8 de febrero de 2011. 
cia", el reconocimiento colectivo, la legitimación del reclamo callejero. Estos son los relatos de quienes habían iniciado su vida laboral y en algunos casos política, en un contexto de descalificación y desmovilización gremial como fueron los ' 90 . Son la generación "hija del presentismo", cuya referencia de lucha y militancia gremial la habían recibido de sus propios maestros, ahora "compañeros". Los eventos de 2007 conformaron la puesta en escena de una nueva generación de dirigentes y el encuentro con la generación anterior, dispuesta a "pasarle la posta”.

Lo que pasa es que el 2007 despertó a mucha gente joven... Entonces ahí es como que, en el 2007 nos encontramos con que teníamos en las conducciones muchos compañeros menores de 40 años, hijos del presentismo. Porque nosotros, tuvimos 16 años de presentismo. Desde el 2007 para atrás, los compañeros que ingresaron desde el 91, 92, que tenemos el presentismo, al 2007, son 15 años, eran hijos del presentismo. $^{35}$

Estos imaginarios por los que transitó la docencia en estos meses de conflicto estuvieron fuertemente atravesados por la idea de "proceso". Esto no deja de ser una característica de todo conflicto, en el sentido de que este es entendido como construcción, como avance y retroceso y reposicionamiento de actores. Pero además, y especialmente, vivido como tal en el propio relato de los protagonistas.

Para ninguno de ellos y ellas lo experimentado era producto de una receta para la acción o decisiones de iluminados vanguardistas; al contrario, cada paso era producto de decisiones colectivas que tenían lugar en los espacios

35. Entrevista 11.5, realizada por Gerardo Avalle, el 10 de febrero de 2011. orgánicos del gremio. El concepto de movimiento devuelve la idea de construcción y de posibilidad, habilitando un interesante proceso de generalización de singularidades que se comenzaron a inventar en los espacios sindicales. Como dicen Félix Guattari y Suely Rolnik lo procesual confronta con lo devenido, aquello prefijado a riesgo de burocratizarse. ${ }^{36}$

En la contienda de Santa Cruz las consignas de "asamblea permanente" y/o "estado de alerta y movilización” cobraron fuerza y relevancia. El "Congreso" -principal instancia orgánicaasumió un carácter "instituyente" para el resto de la docencia, en tanto supuso la posibilidad de innovar en las estructuras y reglas de juego que le dieron lugar, abriendo un umbral donde lo nuevo pasó a conformar parte de los fundamentos desde donde reconstruir la acción colectiva. El gremio triplicó la cantidad de congresos anuales que venía convocando.

Esta instancia de deliberación permanente permitió también abrir al resto de la docencia los espacios del gremio, ponerlos a disposición de las mismas bases. Sin dudas, exigió a la conducción provincial asumir un nivel de exposición y legitimación permanente y, como nunca, "mandar obedeciendo", puesto que la horizontalidad se tornó el marco de la acción. Lejos se estuvo de las posiciones centralistas o espontaneistas, ${ }^{37}$ sino que la función de au-

36. GUATTARI, Félix y ROLNIK, Suely, Micropolitica..., Op. Cit., p. 261.

37. Ídem, p. 247. Los autores citados con anterioridad plantean que es necesario diferenciar las formas de organización política (centralismo, situacionismo, etc.) de la "función de autonomía", en tanto refieren a campos irreversiblemente diferentes, uno el de la decisión, en tanto pone en discusión el mecanismos a partir del cual se decide, su carácter democrático, los órganos a través de los cuales circula esa decisión; y por el otro lado, la autonomía, esto es, la producción de subjetividades, los 
tonomía que comenzó a desplegarse encontró en la dinámica del "consejismo" el mejor transmisor. ${ }^{38}$

\section{Se sabe cuándo empieza, no cuándo termina}

El gremio resolvió iniciar el ciclo lectivo con una jornada de paro, el 5 de marzo de 2007. Al día siguiente, la presidenta del Consejo de Educación anunció un aumento no remunerativo cercano al $15 \%$. Lejos de desactivar la medida de fuerza, este anuncio fue percibido como un agravio al sector. Sumado a ello, la respuesta de las máximas autoridades del gobierno fue una descalificación directa a los docentes: "son los mismos de siempre, vagos y patoteros".

¿qué pasa en pleno conflicto del 2007? el gobierno cuando empieza, las clases deberían haber empezado el 5 de marzo, el día 6 Sancho firma un decreto otorgando un aumento que llamaba básico, otra suma en negro, que representaba aproximadamente un 15 por ciento... como tratando de romper la huelga, jal contrario! Varizat, el famoso Varizat que era ministro de gobierno, sale a decir que -"estos docentes son unos vagos"- ... que -"son unos vagos, unos patoteros y que nosotros no vamos a ceder ante ellos". ${ }^{39}$

modos de prefiguración de los sujetos en el marco de los conflictos.

38. Ver al respecto las críticas elaboradas por Antonio Gramsci a las organizaciones sindicales, en contraposición a la organización en "Consejos de Fábricas”, equivalentes a los soviets rusos. GRAMSCI, Antonio, "Sindicatos y consejos" (I), Disponible en: <http://www.gramsci.org.ar/1917-22/13-sindicatosyconsejos.html>

39. Entrevista 7.30, realizada por Gerardo Avalle, el 7 de febrero de 2011.
La huelga se inició esperando un 30\% de adhesión, que para los congresales había sido definido como un valor aceptable para calificarla como exitosa, dado el contexto desmovilizador que el gobierno promovía. Pero la huelga comenzó con más del 50\% de acatamiento. Las acciones empezaron a planificarse a mediano plazo, puesto que se vislumbraba el inicio de una etapa conflictiva pero no se avizoraba el final. Se abrió un escenario de múltiples temporalidades, donde a nivel micro-estructural ${ }^{40}$ se sucedieron numerosos procesos de colectivización y concientización de las bases sindicales y la población en general. La euforia y la intensidad fueron moneda común en cada acción emprendida.

La decisión política del gremio fue soportar los descuentos y enfrentar el presentismo. Para ello debía garantizar algún ingreso mensual que le permitiera no reeditar la experiencia frustrada de 2004. De ahí que la opción fuera declarar huelgas que no superaran los 10 días mensuales, ya que el requisito para el cobro de asignaciones familiares era desarrollar actividades normales por lo menos durante la mitad del mes. Es por ello que cuando se indaga sobre la vivencia de esos días, los docentes insisten en el carácter estratégico que tenía cada decisión, cada acción desplegada, su duración, la forma de ser comunicada y los lugares donde éstas iban a tener lugar.

40. Micro y macro estructura son conceptos que, inicialmente, tomamos de Teun Van Dijk, para referir a la estructura discursiva de toda enunciación y su materialización. VAN DIJK, Teun, El discurso como estructura y proceso. Estudios sobre el discurso I. Una introducción multidisciplinaria, Gedisa, España, 2000. Complementamos esta conceptualización con la idea de micro y macropolítica de Félix Guattari y Suely Rolnik, como niveles o espacio de actuación y lucha política. GUATTARI, Félix y ROLNIK, Suely, Micropolitica..., Op. Cit., p. 10. 
El carácter estratégico tenía que ver con esa percepción procesual de la que todos eran parte. Las medidas de fuerza se iban "dosificando", sabían que el condicionante salarial sería importante y por eso administraban la cantidad de paros y días trabajados, activaron los fondos de huelga y vieron la necesidad de ampliar la difusión y comunicación del conflicto. La táctica sindical fue "ir llevando de a poco el conflicto", decisión que permitió instaurar un intenso mecanismo deliberativo, que redundó en una fuerte apropiación del conflicto por parte de la docencia y de la población.

Y también creo que la estrategia sindical de... ir, el conflicto, llevándolo de a poco. No sé si te dijeron que el primer mes de conflicto, hubo solamente 10 días de paro, no metimos un paro por tiempo indeterminado, hicimos 10 días, $24,48 \ldots$ se iba dosificando. ${ }^{41}$

Lo imprevisto no era la reacción del Estado, sino del propio cuerpo docente. La primera asamblea pos huelga sorprendió por la masiva concurrencia. Luego promovieron la primera movilización y los cálculos de asistencia habían sido insuficientes. Según los relatos, cuando llegaron a 5.000 personas en la calle la sorpresa no se podía ocultar; cuando superaron las 10.000, empezaron a sentir que estaban y podían ser artífices de un hito en la historia local.

Tal cual. Hasta que en el mes de mayo declaramos tiempo indeterminado. En ese momento logramos introducir la discusión a nivel nacional, que vinieran los medios... estaban prácticamente todos los medios, se juntaron 15.000 personas en la marcha, ¡que acá es mucho! Había, a lo mejor, una

41. Entrevista 8.17, realizada por Gerardo Avalle, el 7 de febrero de 2011. marcha de 15 cuadras de gente, en estos lugares, es muchísima la gente. Nos quemaron el auto, una bomba molotov. Nos sacaron... pusimos la carpa docente en frente de la Casa de Gobierno, la atacaron, la quemaron... todo un conflicto. ${ }^{42}$

Se implementaron numerosas medidas de fuerza y se instaló una "carpa docente", que luego habilitó lo que llamaron "paseo de la dignidad", un corredor de una calle completa donde fueron sumándose otras carpas y/o instalaciones de diferentes gremios de trabajadores del Estado. Mención especial merecen esta "carpa" y el "paseo", en tanto se tornaron espacios de reclamo y prefiguración de prácticas colectivas.

Esa prefiguración presupone la creación de un momento presente y pasajero de la experiencia de la autonomía y la generación de modos alternativos de organización social. En ese marco, las injusticias comienzan a ser denunciadas $\mathrm{y}$ las diferencias y desigualdades entre los sectores subalternos empiezan a desaparecer. Es en esa experiencia breve donde se materializan un conjunto de prácticas que hacen del espacio creado una instancia democrática de encuentro y reconocimiento.

Por eso las prácticas de acción directa tienen en determinadas ocasiones la posibilidad de convertirse en escenarios o plataformas para construir otros modos posibles de habitar el espacio social del que son partes. Y además, como aditivo, logran instalar un conjunto de reivindicaciones y demandas al Estado sin necesariamente pasar a integrar parte de su estructura. Pueden consistir, como señalan

42. Entrevista 6.14, realizada por Gerardo Avalle, el 7 de febrero de 2011. 
Chignola y Mezzadra ${ }^{43}$, en agenciamientos que corren los límites de lo político y exigen a la propia estatalidad (y al capital) modificar su operatoria.

No sólo eran docentes los que circulaban, se sumaron otros trabajadores, otros gremios, otras instituciones; intervino la iglesia, demandó diálogo, sus principales representantes se desplazaban con frecuencia por el paseo exigiendo evitar la violencia a las fuerzas de seguridad ahí apostadas. La carpa se convirtió en un hogar colectivo, empezó con casi nada, luego tuvo espacios y mobiliarios para dormir, comedor, instalaciones eléctricas, talleres de formación, radio comunitaria y calefacción propia.

Con las fuerzas de seguridad ocurrió algo particular. "Los ninjas", como le decían por su vestimenta a las fuerzas federales y provinciales, estaban todo el tiempo apostados frente a la casa de gobierno y prácticamente convivían con los docentes que hacían "guardias" en la carpa. Estos entablaron una relación no confrontativa con los efectivos, intentaban desmoralizarlos y resquebrajar la disciplina interna; buscaban, a partir de la igualdad semántica "trabajadores", provocar una reversión semiótica contra el propio Estado, desnaturalizando la función preventiva/represiva de la institución policial.

Dado que Santa Cruz es una provincia con muy baja población, la cercanía entre los diferentes círculos sociales es mayor y en muchas oportunidades los familiares de los gendarmes eran los mismos docentes en lucha; muchos de ellos habían tenido a los "acampantes" como profesores en el aula, factores que los docentes también supieron aprovechar.

43. CHIGNOLA, Sandro y MEZZADRA, Sandro, “Fuera de la pura política...", Op. Cit., p. 225.
Creo que a los tres meses del conflicto que seguíamos todos ahí en la lucha ... y estaban los gendarmes, los ninja ¿iviste? que estaban todos pa(-) sí ¿viste? y todos así con cascos, con chalecos antibalas, con palos, con esos escudos de acrílico... estaban todos así y estaba una reja por medio estaban los chicos de la escuela de policía, cadetes, que las mamás estaban ahí y algunas habían sido profesoras y estaban del otro lado y nosotros de este lado y nos decían "pásennos un cafecito, hace frío" y pasaban café. ${ }^{44}$

Un conflicto dosificado, debatido, llevado de a poco, pero no por ello lineal y sin sobresaltos. Vinieron también los atentados, las amenazas, las intimidaciones, los atropellos físicos y simbólicos, las contramarchas, las descalificaciones. En lugar de surtir el efecto deseado por la propia estatalidad, estos factores "represivos" operaron como aliciente para la acción, para el fortalecimiento de los marcos orientadores y la generalización ${ }^{45}$ de los mismos, puesto que "la violencia polariza el conflicto" ${ }^{46}$. Desde el lado docente, el conflicto también amenazaba con salirse de cauce: levantar las medidas, radicalizarlas, tomar los Concejos Deliberantes (órganos legislativos municipales), enfrentamientos con las fuerzas de seguridad, escraches a funcionarios, etc.

44. Entrevista 2.1, realizada por Gerardo Avalle, el 2 de febrero de 2011.

45. Adriana González Gil trabaja la categoría de "contextos de violencia" para analizar la creación y modulación de repertorios de acción colectiva en situaciones donde las oportunidades políticas intervienen como elementos que desincentivan la acción, especialmente, ante situaciones de violencia extrema. GONZÁLEZ GIL, Adriana, "Acción colectiva en contextos de conflictividad violenta: una propuesta para su interpretación”, en Circunstancia, Madrid, 2006, № 10, pp. 1-55.

46. DELLA PORTA, Donatella y DIANI, Mario, Los movimientos..., Op. Cit., p. 224. 
Cuando las medidas de fuerza empiezan a sucederse (11 paros en marzo, 12 paros en abril, instalación de la carpa, atentados, descalificaciones mediáticas, intervención del Estado Nacional, fondos de huelga, presencia de fuerzas de seguridad nacional) el conflicto también se generaliza hacia el resto de la población y ante cada acto que era percibido como atropello, mayor cantidad de "audiencia" ${ }^{47}$ pasaba a formar parte de las acciones colectivas.

En el mes de mayo se declara una huelga por tiempo indeterminado, el gobierno nacional dicta la conciliación obligatoria pero, al no haberse recibido oferta salarial previa por parte del gobierno provincial, esta es improcedente y queda sin efecto. Luego, cuando una funcionaria del gobierno provincial dicta la conciliación en el marco de futuras negociaciones, es desautorizada por la propia dirección política local y debe renunciar al cargo.

Kirchner JAMÁS recibió a esta organización, durante sus 12 años de gestión nunca la recibió. Acevedo ${ }^{48}$ jamás nos recibió,

47. La categoría de "audiencia" refiere al sector de la población que se posiciona como espectador del conflicto. Además de ellos, se encuentran los protagonistas y los antagonistas. Dependiendo de la generalización de los marcos del conflicto, esa audiencia puede sumarse al grupo que sostiene la acción colectiva. HUNT, Scott BENFORD, Robert y SNOW, David, "Marcos de acción colectiva y campos de identidad en la construcción social de los movimientos", en GUSFIELD, Joseph y LARAÑA, Eduardo (editores) Los nuevos..., Op. Cit. Algo similar sostendrá Sidney Tarrow respecto de la generación de un ciclo de conflictos, donde los primeros en comenzar a movilizar son aquellos que se encuentran más involucrados en la contienda, pero habilitan el escenario a nuevos actores que se suman e incorporan nuevos reclamos. TARROW, Sidney, El poder..., Op. Cit., p. 60.

48. Gobernador interino durante el periodo 2003-2006 y que sucede a Néstor Kirchner luego de su renuncia.
Sancho ${ }^{49}$ tampoco y luego del conflicto del 2007, que logramos poner no sólo al sector docente sino a la comunidad a favor y con los propios reclamos, porque todo lo que le pasó al sector docente le pasó a los demás sectores, es decir, ¡todos tenían planes transitorios, había gente que estuvo contratada durante 20 años! cuando en realidad la ley establece que a los 6 meses tiene que pasar a planta transitoria y después a planta estable... es decir, esta política de flexibilización la aplicaron para todos lados: flexibilización en el salario, pago en negro, etc., etc., en todos lados y esto hizo que bueno, nosotros fuimos punta de lanza de un reclamo al que se sumó la población y que llevó a la renuncia de Sancho y obligó al Estado a negociar a través de las paritarias... después de 18 años Peralta ${ }^{50}$ nos recibió una sola vez, el Gobernador nos recibió en el año 2008, es la única audiencia que hemos tenido con el gobierno durante todo este tiempo... lo demás se ha conquistado, se ha logrado a través de la lucha. ${ }^{51}$

La carpa docente comienza a tener más fuer$\mathrm{za}$, se suman numerosas organizaciones sindicales; la población asiste a las actividades ahí programadas no sólo para informarse sino para adherir a la "lucha". La casa de gobierno es vallada por completo y se refuerza la seguridad con efectivos federales. En las escuelas, vacías por las medidas desplegadas por los docentes, se realizan actividades para recaudar fondos y sostener económicamente a los docentes en huelga. El gobierno ocupa con fuerzas de seguridad las escuelas.

49. Carlos Sancho fue gobernador interino que sucede a Sergio Acevedo luego de su renuncia (2006-2007).

50. Gobernador interino y luego gobernador electo que sucede a C. Sancho luego de su renuncia (2007-2015).

51. Entrevista 4.5, realizada por Gerardo Avalle, el 4 de febrero de 2011. 
La obscenidad de lo vivido tuvo lugar en dos enfrentamientos que preanunciaron un final favorable para los docentes. La presencia del Presidente de la Nación en su residencia incita a los docentes a manifestarse, las fuerzas policiales cubren y acordonan el domicilio y, si bien no reprimen, detrás de ellos se encontraba otro grupo identificado por los docentes como "patotas del partido" que propinaban golpes y arrojaban piedras. Días antes, días después, uno de los funcionarios del gobierno atropella a varios docentes con su vehículo, algunos de ellos terminan hospitalizados y otro tanto con heridas leves. Lejos de intimidar, estas medidas reforzaron las convicciones de quienes había emprendido la lucha, ya habían "elegido".

¿viste lo que paso en la marcha?" -"No, no vi”; -“¿vos fuiste?”, -“Si, ¿Qué paso?”, -“No, que Varizat ${ }^{52}$ atropelló a la gente"... al otro día, otra vez, todos allá (a Casa de Gobierno) ¿viste? Tiramos las vallas, todo ¿viste? y se armó, rompieron un vidrio y bueno, yo no me pongo ni que no, ni que sí, ni que estaba bien, ni que estaba mal. Mal porque no se tienen que hacer esas cosas, pero ¿Por qué fue?, digamos, la gente estaba re caliente... había atropellado gente. ${ }^{53}$

Días después renuncia el gobernador interino; un legislador en quinto orden para la sucesión del ejecutivo (luego gobernador) venía tomando intervención en las negociaciones, que ya no tenían lugar en Santa Cruz sino directamente en el Ministerio de Trabajo de la Nación. La oferta fue un aumento salarial remunerativo, el blanqueo de los restantes ítems salariales y la eliminación del presentismo. El gremio firma

52. Ex-ministro de gobierno de la provincia de Santa Cruz durante el año 2007.

53. Entrevista 5.22, realizada por Gerardo Avalle, el 6 de febrero de 2011.

40 el acuerdo, el presentismo es oficialmente derogado el 11 de octubre y el 3 de noviembre de 2007 el gremio resuelve levantar la "histórica" carpa de la dignidad.

\section{Reflexiones finales}

La posibilidad de análisis es tan amplia como sentidos emergentes de los discursos tratados. Sin embargo, uno puede a partir de una mirada microfísica de las prácticas sindicales como la que hemos propuesto, trazar aquellos lineamientos que son los que permitieron dar forma a una contienda sindical paradigmática para el resto de las luchas docentes en el país. La persistencia en el enfrentamiento, la represión y el asedio estatal al gremio docente y la prolongación del conflicto la ubica dentro de los eventos contenciosos más notorios dentro de las luchas sociales de los últimos años.

Lo que intentamos rescatar aquí fue la potencia de la palabra hecha praxis, esto es, la capacidad performativa del lenguaje, el efecto del discurso como dimensión constitutiva de la realidad. De ahí que un análisis hermenéutico de los relatos y experiencias de lucha nos permitió reconstruir la contienda sindical docente de Santa Cruz, y la emergencia de subjetividades políticas en esa misma confrontación.

Los significantes más robustos que aparecieron en este análisis podrían sintetizarse en la asamblea como lugar de proyección y generalización de las singularidades más moleculares, y la escuela como fuente de autonomía y desmercantilización. Son esos los dos espacios más claros de territorialización de los procesos de construcción de subjetividades políticas, dos espacios que condensan gran parte de las 
acciones colectivas, dando cuenta del carácter social y no individual de los mismos. Son, a su vez, y desde la perspectiva del análisis de discurso, dos campos semánticos condensan gran parte de las significaciones aquí tratadas, que lejos de un relato secuencial de hechos, representan en núcleo argumentativo o semiótico de una historia de luchas y sujetos organizados.

La eventualidad de los agravios y las condiciones materiales desventajosas no nos permiten explicar el sentido político de un conflicto. Esta emergencia de la acción contestataria no deja de ser defensiva-reivindicativa. La posibilidad de agenciamiento y generalización está en que esos procesos de "auto-pensamiento" logren inscribirse por fuera del registro de la "parte", del segmento que representan. Esa articulación y encuentro de las partes, siempre heterogéneas y cambiantes, es lo que les permite operar como instancia de construcción colectiva innovadora, de modo que las luchas no sean absorbidas por los mecanismos clásicos de procesamiento de conflictos, y le saquen, en consecuencia, la posibilidad de correr el límite de lo permitido por la política, exigiendo de ese modo que altere al menos su forma de operar.

No hay, en este sentido, precondiciones ideológicas o programas políticos necesariamente predefinidos y actuando por detrás de los posibles adherentes. Aparece, en cambio, una necesidad concreta, el reconocimiento de una situación de exclusión y de imposibilidad; y frente a ella un escenario donde entran a jugar un conjunto de estrategias, prácticas y actores que sostienen posiciones de negociación y confrontación. El registro que asuma esa demanda, sea o no bajo el lenguaje de "derecho a", se torna central para identificar si ese devenir colectivo queda preso de los mecanismos disciplinares como el salario y la ley, o logra erigirse como un lenguaje no juridizado, como una posición/afirmación que busca alterar los márgenes del espacio de contienda.

Como advertimos al principio, decidimos problematizar la cuestión sindical desde la perspectiva de los propios participantes de esos conflictos. Esa opción metodológica de indagar a partir de la mirada de los sujetos se vio reforzada con una perspectiva teórico-política que pretende dar cuenta de la economía del poder en un reducto sindical, por lo que no puede sino preguntarse por el modo de constitución de los conflictos que ahí se generan.

En este sentido, es precisamente en aquellos espacios en los que el conflicto aparece como el momento central de construcción de otro mundo posible, $\mathrm{u}$ otro modelo posible de sociedad, donde las voces discordantes del mundo salarial registrado, con mayor estabilidad laboral, reactivan la confrontación, y al hacerlo radicalizan el espacio político, puesto que ponen en cuestión y debate los significados de esa sociedad o mundo común.

Precisamente, fueron las experiencias locales, con la estructura sindical como garante, pero especialmente las formas organizativas sui generis constituidas en el marco de las revueltas provinciales las que dieron mayor dinamismo a las contiendas, aportando grados de autonomía significativos para delinear la política gremial en pleno conflicto. Fue en esos momentos donde la estructura y especialmente la dirigencia sindical vieron claramente menguar su poder de decisión frente a quienes sostenían realmente las luchas, las bases sindicales.

Este aspecto ampliamente trabajado en la contienda de Santa Cruz queda expreso claramen- 
te que los elementos movilizadores se asocian más a emociones, sentires colectivos, indignaciones, broncas y dolores, rabia devenida en rebeldía, más que a altos niveles de pobreza y desempleo estrictamente. Sin duda estos son factores condicionantes, pero requieren de: un proceso de significación colectiva de esa injusticia, la identificación de esa situación como un problema que atraviesa a todos, la construcción de demandas y equivalencias que sean interpretadas como comunes y no sectoriales, y principalmente, ofrecer como marco de interpretación un proyecto alternativo o defensivo al estado actual de las cosas. La autonomía es, en este sentido, un desafío para pensar y construir otros mundos y habilitar otras prácticas y modos de habitar el escenario político.

$\propto \tilde{e} \propto$

Recibido: 03-05-2017

Aceptado: 03-11-2017

Publicado: 07-06-2018 


\section{Bibliografía}

ALTAMIRA, Carlos, Los marxismos del nuevo siglo, Biblos, Buenos Aires, 2006.

AUZOBERRÍA, Miguel, Los días de Cépernic. Una bistoria del Peronismo de Santa Cruz, Editorial Dunken, Buenos Aires,2014.

BAKMAS, Gabriel, Integración, exclusión y criminalización de la protesta. Felafacs, Santiago de Chile, 2002.

CARDINI, Alejandra y GESSAGHI, Victoria, "Provincia de Santa Cruz", en Informe Proyecto Las provincias educativas, CIPPEC, Buenos Aires, 2003.

CHIGNOLA, Sandro y MEZZADRA, Sandro, "Fuera de la pura política. El laboratorio global de la subjetividad”, en ALTAMIRA, Carlos, Politica y subjetividad en tiempos de governance, Waldhuter, Buenos Aires, 2013, pp. 203-234.

CIUFFOLINI, María, Resistencia y Conflicto: Luchas Sociales Urbanas en Córdoba post- 2001, EDUCC, Córdoba, 2010.

CROUCH, Colin y PIZZORNO, Alejandro, El resurgimiento del conflicto de clases en Europa occidental a partir de 1968, Centro de Publicaciones, Ministerio de Trabajo y Seguridad Social, Madrid, 1991.

DELLA PORTA, Donatella y DIANI, Mario, Los movimientos sociales, CIS, Madrid, 2011.

DELLA PORTA, Donatella, "Protest, Protesters, and Protest Policing: Public Discourses in Italy and Germany from the 1960's to the 1980's”, en GIUGNI, Marco, MCADAM, Doug, y TILLY, Charles, How Social Movements Matter, University of Minnesota Press, Minneapolis, 1999, pp. 66-96.

ELSTER, John, El cemento de la sociedad. Las paradojas del orden social, Gedisa, Barcelona, 1992.

FOUCAULT, Michel, El orden del discurso, Tusquets, Buenos Aires, 1987.

GONZÁLEZ GIL, Adriana, “Acción colectiva en contextos de conflictividad violenta: una propuesta para su interpretación”, en Circunstancia, Madrid, 2006, No 10, pp.1-55.

GRAMSCI, Antonio, "Sindicatos y consejos” (I), LON, en <http://www.gramsci.org.ar/>, 1919.

GUATTARI, Félix y ROLNIK, Suely, Micropolitica. Cartografías del deseo, Tinta Limón, Buenos Aires, 2013.

HUNT, Scott, BENFORD, Robert y SNOW, David, “Marcos de acción colectiva y campos de identidad en la construcción social de los movimientos”, en Gusfield, Joseph y Laraña, Enrique, (editores) Los nuevos movimientos sociales: de la ideología a la identidad, CIS, Madrid, 1994.

KLANDERMANS, Bert, "La construcción social de la protesta y los campos pluriorganizativos", en GUSFIELD, Joseph y Laraña, Enrique, (editores) Los nuevos movimientos sociales: de la ideología a la identidad, CIS, Madrid, 1994. 
LAZZARATO, Maurizio, Politicas del Acontecimiento, Tinta Limón, Buenos Aires, 2006.

LUQUE, Élida, MARTÍNEZ, Susana, AUZOBERRÍA, Miguel y HUENUL, Hugo, "Conflictos sociales en la provincia de Santa Cruz. Los años noventa”, en Documento de Trabajo PIMSA, Buenos Aires, 2003, No 41.

McADAM, Dough, TARROW, Sidney y TILLY, Charles, Dinámica de la contienda politica, Hacer Editorial, Barcelona, 2005.

MELUCCI, Antonio, L'invenziones del presente: movimiento, identità, bisogni individuali, Il Mulino, Bologna, 1982.

NEGRI, Toni, Fin de siglo, Barcelona, Paidós, 1992.

SVAMPA, Maristella y GARGARELLA, Roberto, "E1 derecho y la protesta social", en Página 12, Buenos Aires, 04/11/2003.

TARROW, Sidney, El poder en movimiento. Los movimientos sociales, la acción colectiva y la politica, Alianza, Madrid, 1997.

TOURAINE, Alaine, Los Movimientos Sociales, Almagesto, Buenos Aires, 1991.

VAN DIJK, Teun, El discurso como estructura y proceso. Estudios sobre el discurso I. Una introducción multidisciplinaria, Gedisa, Madrid, 2000. 